\title{
Powder Injection Moulding: processing of small parts of complex shape
}

\author{
José M. Torralba* \\ IMDEA Materials Institute, \\ Universidad Carlos III Madrid, Spain \\ E-mail: josemanuel.torralba@imdea.org \\ ${ }^{*}$ Corresponding author
}

\section{Javier Hidalgo and Antonia Jiménez-Morales}

Department of Materials Science and Engineering, Universidad Carlos III Madrid, Spain

E-mail: jhidalgo@ing.uc3m.es

E-mail: toni@ing.uc3m.es

\begin{abstract}
Powder Injection Moulding (PIM), Metal Injection Moulding (MIM) when is limited to metals, is a fabrication route of parts with the final shape desired. This process combines the high capability of polymer injection moulding to produce complex shapes with the advantages of a powder route to process metallic, ceramic or composites materials. The process has some limitations that comes from different technological steps involved in the production of the part (feedstock production, injection, debinding and sintering). All of these different steps can be industrially controlled, being the PIM process a real alternative to produce complex parts in a high rate production method that can compete with many other processing methods to produce materials. In this work, we will go through the different steps of this manufacturing process, making special emphasis on the solutions provided by the powder technology group of the University Carlos III of Madrid (UC3M).
\end{abstract}

Keywords: PIM; powder injection moulding; MIM; metal injection moulding; feedstock development; debinding process; sintering.

Reference to this paper should be made as follows: Torralba, J.M., Hidalgo, J. and Jiménez-Morales, A. (2013) 'Powder Injection Moulding: processing of small parts of complex shape', Int. J. Microstructure and Materials Properties, Vol. 8, Nos. 1/2, pp.87-96.

Biographical notes: José M. Torralba is Deputy Director of Institute IMDEA Materials. He is a Professor of MSE at Universidad Carlos III de Madrid. He has published more than 350 scientific papers (132 in the JCR in more than 1000 cites), has supervised $17 \mathrm{PhD}$ thesis and 50 Diploma thesis. In 1999, he received the 'Professor Fryderyk Staub' award from the Silesian University of Technology (Poland), in 2001 the Honoris Causa Doctorate from the Technical University of Cluj-Napoca (Rumania), in 2005 the Slovak Academy of Sciences Award and in 2007 Honoris Causa Doctorate by the University of Craiova (Rumania). He has been involved in 32 competitive projects and is the PI in 20 of them. He has managed several research grants with industries, 
including the Höganäs Chair in Powder Metallurgy. He is Regional Editor (for Europe) of Journal of Materials Processing Technology and Journal of Achievements in Materials and Manufacturing Engineering.

Javier Hidalgo received his Industrial Engineer and MS in Material Science and Engineering from the Carlos III University of Madrid in Madrid. Presently, he is a $\mathrm{PhD}$ student at the same University. He is a co-owner of a patent and co-authored several publications and congress contributions in the field of powder injection moulding.

Antonia Jiménez-Morales received her Degree in Chemical Sciences from Autonomy University of Madrid in Madrid and her $\mathrm{PhD}$ from the Carlos III University of Madrid in Madrid. She is a member of Electrochemical Society (ECS) and the European Internet Centre for Impedance Spectroscopy. She has co-authored over 25 publications on various aspects of electrochemical materials and powder injection moulding and she has co-authored over 30 works published in book chapters with ISBN. She is a co-owner of three patents, and co-author of more than 65 congress contributions. She has been PI of seven Research Projects and now she is PI of two more. She has been a member of the Organising Committee of seven National and International Conferences, and Chairman of two sessions of International Conferences. In addition, she is a reviewer for several journals included in JCR.

This paper is a revised and expanded version of a paper entitled 'Torque rheology of zircon feedstocks for powder injection moulding', presented at Feedstock Development for Powder Injection Molding of Zirconium Silicate PM2011 Euro Congress - Powder Injection Moulding - Processing, Barcelona, Spain, 9-12 October, 2011.

\section{Introduction}

Metal Injection Moulding (MIM) is a materials processing route to produce parts of very complex shape at very low cost. It has all the benefits of plastic injection moulding with the advantages of powder metallurgy as near net shape processing for metals and ceramics. When ceramic powders are involved in the process we call it Powder Injection Moulding (PIM). Figure 1 shows a flow chart of the PIM process. The first step of the process is the selection of the proper metallic or ceramic powders (in terms of size, shape or granulometric distribution), with the desired composition and binder system that will allow the injection process. The selection of the binder will influence not only the injection process, but the debinding process too. Later, we will discuss some of the possible options for this binder system. Once the feedstock is produced, we can inject it to produce a green part. This green part should be debounded, and here the discussion is focussed to choose the kind of debinding method that can be followed (solvent debinding, catalytic debinding, thermal debinding, combinations, etc.). In this technology the debounded part is designated a brown part. The brown part should be subsequently sintered to achieve the final properties (density, mechanical properties or other properties) in the part. 
Figure 1 PIM process chart

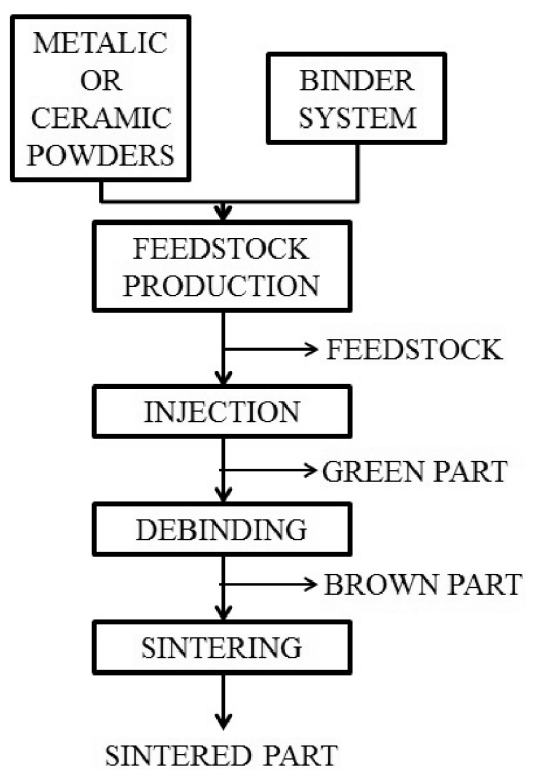

Average size of PIM parts is around few centimetres, but there are examples from few milimetres, but in the last years the $\mu$ PIM technology has been developed in which the final size of the part is under $1 \mathrm{~mm}$ in the large dimension (this means parts with no more than a few hundreds of microns are in the large dimension, and usually sizes less than $100 \mu \mathrm{m}$ are in the larger dimension) (Piotter et al., 2003). The $\mu$ PIM technology has opened the interesting field of nanotechnologies to this processing method (Supriadi et al., 2007). MicroMIM is a process to produce micro devices at low cost, high performance and with good dimensional control. Dimensions under 30-40 $\mu \mathrm{m}$ have been already achieved. To date, dimensions under 30-40 $\mu \mathrm{m}$ could be achieved (Liu et al., 2003), so, if the used powder has an average size of $5 \mu \mathrm{m}$, we can have a maximum of six particles in this device. As can be deduced, the main constraint in this technology is the size of the particles. For this reason, the $\mu$ PIM was first developed (with ceramics that usually have lower particle size), and one of the tendencies of the technology is to use nanopowders with dimensions lower than $100 \mathrm{~nm}$ (Supriadi et al., 2007).

This technology has a lot of challenges that can be attained by modifying some of the technological parameters that are commonly used in MIM (Loh et al., 2005): it is essential to have a suitable binder system with low viscosity, giving easy mould filling and higher green strength; suitable moulding parameters, such as higher melt and mould temperatures and of course, the particle size should be smaller than in conventional MIM. To improve the performance of $\mu \mathrm{MIM}$, further materials and process development have been carried out (Piotter et al., 2003): modelling tools must be involved in any development and fine metal powders (even close to the nano size) have been used.

Another interesting technological development in the PIM process is the adaptation of the call "two colours injection moulding" of the plastic industry, that is usually called 
co-injection in the PIM field (Imgrund et al., 2005; Dourandish and Simchi, 2009; Simchi and Petzoldt, 2010). To produce parts with the two-colour MIM technology, many technological problems must be overcome, with the main one being controlling distortions during heating, sintering and cooling produced by the possible different thermal expansion coefficients of the two injected materials. Regarding this issue, one interesting possibility is that the use of stainless steel of different grades is based on the mixture of steels with different magnetic characters while maintaining similar thermal characteristics. This is the development described in Simchi and Petzoldt (2010) where two different stainless steels were injected (a combination of a non-magnetic and a ferromagnetic stainless steel, $316 \mathrm{~L}$ and $17-4 \mathrm{PH})$. The possibility of two-colour MIM is not limited to a combination of two metallic materials. It is also possible to use a combination of metal and ceramic, such as cemented carbides (Imgrund et al., 2005) or yttria-stabilised zirconia (Dourandish and Simchi, 2009).

We will discuss some approaches for the different steps including different alternatives in the materials selection.

\section{Experimental process}

Optimisation of the feedstock production is highly important to consider different parameters: optimal solid loads, viscosity, flow index, yield stress, shear rate and activating energy of the feedstock.

The main set of properties to be characterised in a feedstock are those related to viscosity.

The viscosity is a property of fluids due to the intermolecular forces (i.e., between their polymeric chains in the case of the polymeric materials), which impede changes in a finite time, so that when a force is applied the fluid presents a certain resistance to flow. This magnitude can be obtained as the relationship between the efforts necessary to obtain a certain deformation rate in the fluid (equation (1)):

$$
\eta=\sigma / \gamma,
$$

where $\eta$ is the viscosity [Pa's], $\sigma$ is the shear stress [Pa] and $\gamma$ is the shear rate $\left[\mathrm{s}^{-1}\right]$. Studies performed by German (1997) have demonstrated that in order to avoid problems during the injection stage, the feedstock viscosity must be less than $1.000 \mathrm{~Pa} \cdot \mathrm{s}$ at shear rates between 100 and $1.000 \mathrm{~s}^{-1}$.

We can have a measure of the viscosity of a feedstock by using a capillary reometer. In this equipment we force the feedstock to pass through a hole of a measured diameter (like an extrusion process) with a controlled force and at a measured rate. In Figure 2 we can see, as an example, the different values obtained for a superalloy feedstock, based on Polyethylene (PE) and different amounts of stearic acid. We can have another approach to the viscosity through the measure of the torque in an instrumentalised torque. This is a good way to get information to obtain the optimal solid load of powder in the binder system. In Figures 3 and 4, we can see two different examples. The first one is related to a stainless steel feedstock and the second to a glass powder feedstock. 
Figure 2 Viscosity of a PE-based feedstock of superalloy for different contents of stearic acid and different shear rates (see online version for colours)

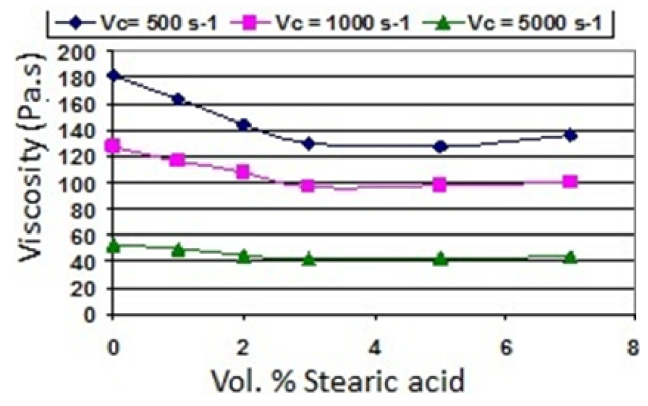

Figure 3 Torque vs. stainless steel powder loadings added to the binder evolution (see online version for colours)
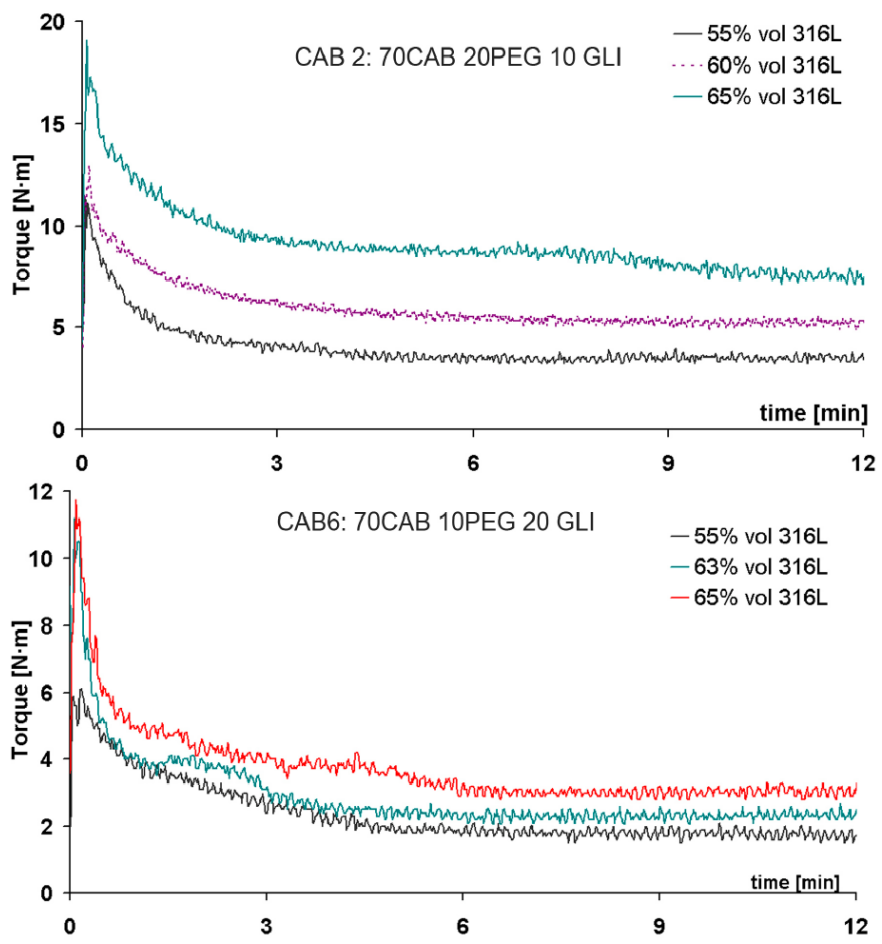

By means of the Ostwald and Waele's power law - Ostwald (1925) and De Waele (1923), the pseudoplastic materials behaviour can be described, or what is the same, materials whose viscosity diminishes when the shear rate $(\gamma)$ increases. This law is given by the following expression (2):

$$
\sigma=K \cdot \gamma^{n}
$$

where $K$ is a constant. The exponent ' $n$ ' is the denominated index of the power law or flow index and provides the sensitivity degree of the viscosity with respect the shear rates variations. An exponent ' $n$ ' smaller than the unit indicates that the material is 
pseudoplastic, increasing this nature according to ' $n$ ' makes lower. The flow index is obtained from the slope of the resulting straight line when the shear stress vs. the shear rate is represented in double logarithmic scale.

Figure 4 Torque vs. glass powder loadings added to the binder evolution (see online version for colours)

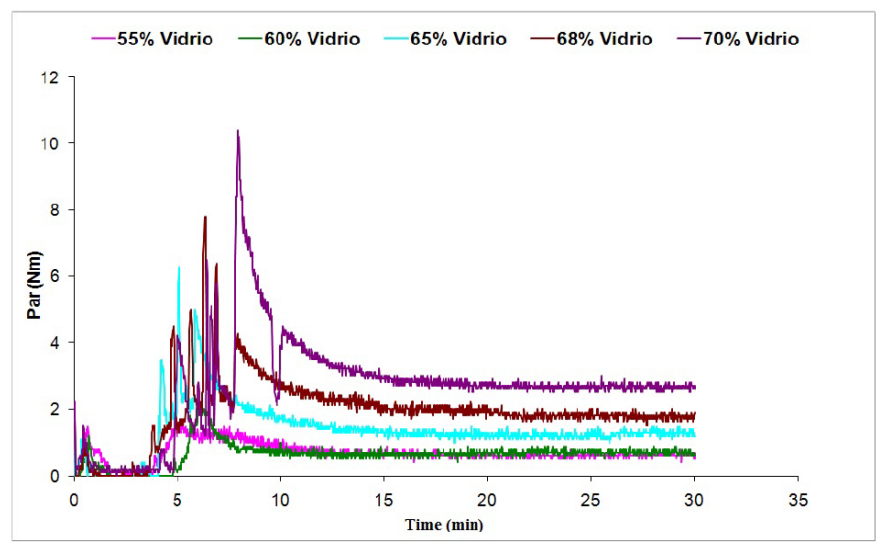

The minimum effort that is necessary to apply to a material in order that it begins to flow is known as yield stress. This parameter which can be estimated using Casson's model is given by expression (3), where $\sigma_{0}$ is the yield stress. High yield stress values can be damaging for the injection process producing an incomplete filled mould.

$$
\sigma^{1 / 2}=\sigma_{0}^{1 / 2}+\eta \cdot \gamma^{1 / 2}
$$

The activation energy is a measurement of the dependence of viscosity on temperature. This dependency has a great importance in PIM since, if it is very high, it can cause abrupt changes of viscosity during mould filling in the injection stage that can lead to defects in the parts. High values of $E a$ imply a high dependence of viscosity on the temperature and, therefore, they are harmful to the injection process. The relationship between viscosity and temperature is like Arrhenius type as is shown in this expression (4):

$$
\eta(T)=\eta_{0} \exp (E a / R T),
$$

where $E a$ is the activation energy and $R$ is the ideal gas constant. The activation energy is obtained by calculating the slope of the resulting straight line when the logarithms of viscosity and the inverse of the temperature are represented.

\section{Results and discussion}

An important part of the binder/feedstock characterisation is its thermal behaviour. This is crucial for understanding its debinding process. The thermal characterisation can be carried out in a differential thermal analyser at high temperature. 
Once the feedstock has been properly characterised and produced, the desired shape should be injected. The injected part is called green part. The organic components of the green par should be extracted/eliminated in order to obtain a polymer-free material that should be sintered in order to obtain the final properties. We can choose among the following debinding methods.

\subsection{Catalytic debinding}

The "polyacetal binder systems" should be debounded in a gaseous acid environment (usually highly concentrated nitric or oxalic acid) at a temperature near $120^{\circ} \mathrm{C}$ (a temperature slightly lower than the softening of the binder system). The acid acts as catalyser in the degradation of the polymer binder system. All the reaction products are burnt in a natural gas flame at temperatures above $600^{\circ} \mathrm{C}$. This debinding method in these feedstocks is highly efficient, producing a well-interconnected porosity after short times (about two or three hours depending of the size of the component). In Europe this is the most extended method to produce parts. The main drawback of this method is the combination of aggressive acids (as nitric) with relatively high temperatures that promotes corrosion in the surrounding equipments.

\subsection{Solvent debinding}

To remove the binder by this way, the binder composition should include a constituent that can be dissolved in a liquid at low temperature so that a network of interconnected porosity is formed in the part while being immersed in the solvent. Some possible solvents used in MIM are acetone, ethanol (and other alcohols), hexane and water. Except water, all the other options (organic options) can produce health problems if precautions are not taken. Solvent debinding needs longer times than catalytic binder removal, but investment cost and environmental problems (especially with water) are much lower.

\subsection{Thermal debinding}

The binder system can be eliminated by burning the polymers by heating the feedstock at temperatures at which the main polymers decompose or degrade. Temperatures can reach $800^{\circ} \mathrm{C}$ depending on the binder system, which requires times longer than catalytic debinding. In order to reduce these long times, a combination of solvent and thermal debinding can be used.

Conventional binder systems using PE as base can be easily debounded with a double cycle of solvent debinding (i.e., using heptane) and thermal debinding (Herranz et al., 2005). By using systems based on waxes, the debinding operation can be shortened. Hidalgo et al. (2010a) demonstrated the use of different waxes to produce a binder system that allows to get a reliable feedstock. The amount of different waxes should be selected according to different needs of the process, but optimum processing parameters can be reached by different amounts of waxes. This kind of feedstock systems based on waxes can be properly injected and debounded. 
Recently some systems based on polysaccharides tend to find more ecological degradation, thus avoiding petrol derived products. In Hidalgo et al. (2010b, 2012), Cellulose Acetate Butyrate (CAB) is used as main component of the binder system. Like other mentioned thermoplastics, $\mathrm{CAB}$ has excessive viscosity for MIM alone and Polyethylene Glycol (PEG) and glycerine are used as non-harmful plasticisers. The viability of the application of binder systems based on mixtures of these constituents will be contrasted with the addition of high solid loadings of powder. After this study of applicability to PIM technology of binder systems based on polysaccharides, it can be concluded that these binder systems are feasible.

In order to allow a better injection and debinding process, small and spherical powders are more suitable (Hidalgo et al., 2010b, 2012). In Figure 5, we can see the typical morphology and size distribution of a metallic powder suitable for the MIM process. But powders with different sizes and with a wider granulometric distribution can be used to make the process cheaper. In Contreras et al. (2009), it was verified that the particle shape and size of the powder used in MIM have a great influence on the rheological properties of the powder-binder mixtures. The use of powders with irregular particle morphology leads to an increase in viscosity, in the yield stress and, in general, to a worsening of the rheological properties. The coarse particle size powder presented the worse rheological properties and the results showed that over a solids loading in volume of $58 \%$ the obtained mixtures do not possess the rheological conditions necessary to be injected. The powder-binder mixtures fabricated from fine and coarse powders showed a reduction in viscosity and improved rheological properties in comparison with those in which the fine or coarse powders were used separately; therefore, using these mixtures the injection process could be improved simultaneously such that the production costs are reduced. These later powders need more care for the debinding process in terms of time and heating/cooling rates (Contreras et al., 2009).

Once powders are debinded, the part can be sintered till the final properties are reached. After sintering, theoretical densities of $95-97 \%$ can be reached. In Figure 6 we can see, as an example, a bronze part in green, brown and sintered state.

MIM is a high versatile technology that can be used to produce different kinds of alloys and by different ways depending on the used feedstock. Carlos III of Madrid University, feedstocks have been successfully developed based on thermoplastics (PE and polypropylene (PP)) mixed with paraffin wax and stearic acid, binders based on mixes of different waxes (paraffin, polyethylene wax, carnauva wax, etc.) and binders based on CAB. With these wide range of self-made feedstocks, bronze, stainless and high-speed steels, ferrites, superalloys and different ceramics were effectively obtained.

\section{Conclusions}

MIM is a feasible technology which combines the flexibility of powder metallurgy in the sense of the possible materials to be produced (any material that can be available in powder shape), with the flexibility of polymer injection moulding in the sense of the complexity of the shapes that can be reached. MIM can compete in surface finishing and tolerances with investment casting. With MIM processing technique micro parts as well as biomaterial can be successfully processed/fabricated. 
Figure 5 Up: Morphology of the AISI 4140 powder. Down: Size distribution of the AISI 4140 powder (see online version for colours)
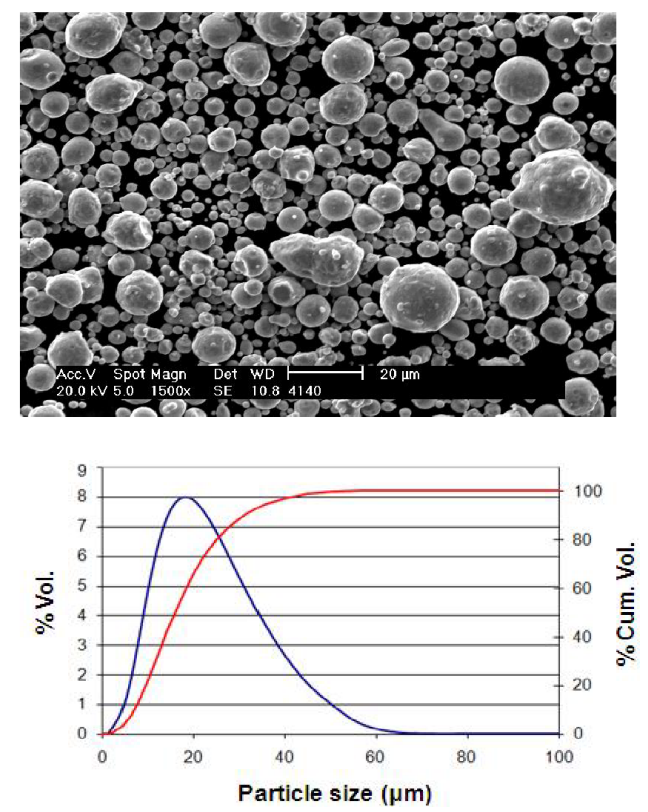

Figure 6 Bronze part, from left to right: green, brown and sintered (see online version for colours)

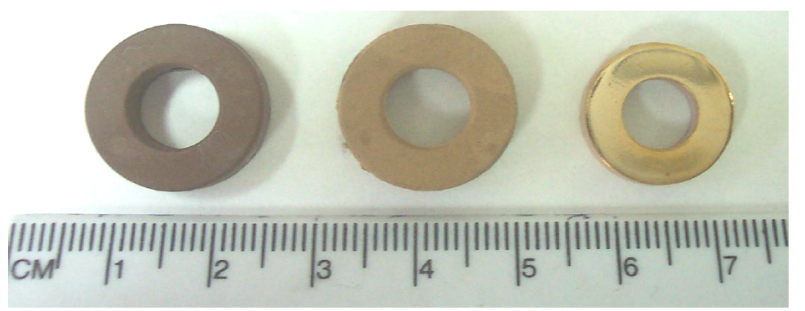

\section{References}

Contreras, J.M., Jimenez-Morales, A. and Torralba, J.M. (2009) 'Fabrication of bronze components by metal injection moulding using powders with different particle characteristics', Journal of Materials Processing Technology, Vol. 209, Nos. 15-16, pp.5618-5625.

De Waele, A. (1923) 'Viscometry and plastometry', Journal of Oil and Color Chemistry Association, Vol. 6, No. 1, pp.33-69.

Dourandish, M. and Simchi, A. (2009) 'Study the sintering behavior of nanocrystalline 3Y-TZP/430L stainless-steel composite layers for co-powder injection molding', Journal of Materials Science, Vol. 44, No. 5, pp.1264-1274.

German, R.M. (Ed.) (1997) Injection Molding of Metals and Ceramics, By Metal Powder Industries Federation, Princeton, USA.

Herranz, G., Levenfeld, B., Varez, A. and Torralba, J.M. (2005) 'Development of new feedstock formulation based on high density polyethylene for MIM of M2 high speed steels', Powder Metallurgy, Vol. 48, No. 2, pp.134-138. 
Hidalgo, J., Contreras, J.M., Baile, B., Jiménez-Morales, A. and Torralba, J.M. (2010a) 'Rheological and thermal behavior of powder injection moulding (PIM) feedstocks fabricated with binder systems based on waxes', Proceedings of World PM2010 Powder Metallurgy World Congress \& Exhibition, October 2010, Florence, Italy, Published in electronic format.

Hidalgo, J., Contreras, J.M., González, S., Jiménez-Morales, A. and Torralba, J.M. (2010b) 'Rheological behavior of powder injection moulding (PIM) feedstocks fabricated with a thermoplastic binder system based on polysacharides', Proceedings of World PM2010 Powder Metallurgy World Congress \& Exhibition, October 2010, Florence, Italy, Published in electronic format.

Hidalgo, J., Jimenez-Morales, A. and Torralba, J.M. (2012) 'Torque rheology of zircon feedstocks for powder injection moulding', Journal of the European Ceramic Society, Vol. 32, No. 16, pp.4063-4072.

Imgrund, P., Rota, A., Petzoldt, F. and Simchi, A. (2007) 'Manufacturing of multi-functional micro parts by two-component metal injection moulding', International Journal of Advanced Manufacturing Technology, Vol. 33, Nos. 1-2, pp.176-186.

Liu, Z.Y., Loh, N.H., Tor, S.B., Murakoshi, Y., Maeda, R., Khor, K.A. and Shimidzu, T. (2003) 'Injection molding of 316L stainless steel microstructures', Microsystem Technologies, Vol. 9, No. 6, pp.507-510.

Loh, N.H., Tor, S.B., Tay, B.Y., Murakoshi, Y. and Maeda, R. (2003) 'Micro powder injection molding of metal microstructures', Materials Science Forum, Vols. 426-432, No. 5, pp.4289-4294.

Ostwald, W. (1925) 'Ueber die Geschwindigkeitsfunktion der Viskositat disperser systeme', Kolloid-Z, Vol. 36, No. 1, pp.99-117.

Piotter, V., Merz, L., Ruprecht, R. and Hausselt, J. (2003) 'Current status of micro powder injection molding', Materials Science Forum, Vols. 426-432, No. 5, pp.4233-4238.

Simchi, A. and Petzoldt, F. (2010) 'Cosintering of powder injection molding parts made from ultrafine WC-Co and 316L stainless steel powders for fabrication of novel composite structures', Metallurgical and Materials Transactions A, Vol. 41A, No. 1, pp.233-241.

Supriadi, S., Baek, E.R., Choi, C.J. and Lee, B.T. (2007) 'Binder system for STS 316 nanopowder feedstocks in micro-metal injection molding', Journal of Materials Processing Technology, Vols. 187-188, No. 12, pp.270-273. 